\title{
Identification and prioritization of critical success factors in faith-based and non- faith-based organizations' humanitarian supply chain
}

\author{
Muhammad Azmat ${ }^{1 *}$ D, Muhammad Atif ${ }^{2}$ and Sebastian Kummer ${ }^{1}$
}

\begin{abstract}
In the last few decades, an exponential increase in the number of disasters, and their complexity has been reported, which ultimately put much pressure on relief organizations. These organizations cannot usually respond to the disaster on their own, and therefore, all actors involved in relief efforts should have end-to-end synchronization in order to provide relief effectively and efficiently. Consequently, to smoothen the flow of relief operation, a shared understanding of critical success factors in humanitarian supply chain serves as a pre-requisite for successful relief operation. Therefore, any member of the humanitarian supply chain might disrupt this synchronization by neglecting one or several of these critical success factors. However, in this study, we try to investigate how faith-based and non-faith-based relief organizations treat these critical success factors. Moreover, we also try to identify any differences between Islamic and Christian relief organizations in identifying and prioritizing these factors. To achieve the objective of this study, we used a two-stage approach; in the first stage, we collected the critical success factors from existing humanitarian literature. Whereas, in the second stage, using an online questionnaire, we collected data on the importance of selected factors from humanitarian relief organizations from around the world in collaboration with World Association of Non-Governmental Organizations (WANGO). Later, responses were analyzed to answer the research questions using non-parametric Binomial and Wilcoxon Rank-Sum tests. Test results indicate that for RQ1, two but all factors are significant for successful relief operation. For RQ2, we found significant differences for some CSF among faith-based and non-faith-based relief organizations. Similarly for RQ3, we found significant differences for some CSF among Islamic and Christian relief organizations.
\end{abstract}

Keywords: CSF, KSF, Success factors, Humanitarian supply chain, Relief organizations, Faith-based organizations, FBO, Islamic organizations, Christian organizations

\section{Introduction}

Relief organizations are facing more significant challenges due to the increase in the frequency of disaster incidences Tatham and Houghton 2011 (refer to Figure in Appendix). Sudden and augmented occurrences of natural disasters put much pressure on relief organizations. They are expected to assist the victims with greater effectiveness and efficiency, and with an overall objective of minimizing the impact of

\footnotetext{
*Correspondence: mazmat@wu.ac.at; m.azmat@live.com

${ }^{1}$ Institute for Transport and Logistics Management, WU, Vienna University of

Economics and Business, Welthandelsplatz 1, 1020 Vienna, Austria

Full list of author information is available at the end of the article
}

disaster (Ngwenya and Naude 2016). Typically, a relief operation consists of several different actors like host government, military, international, regional, or local relief organizations, and private sector companies (Costa et al. 2012). Many of these participants might have different mandates, capacities, logistics expertise, and interests. However, none of the actors has adequate means to respond to the disaster effectively and efficiently on its own (Balcik et al. 2010).

Moreover, some researchers like Fountain et al. 2004, Paulson and Menjivar 2012, Benedetti 2006, McLachlin et al. 2009, Aijazi and Panjwani 2015, and Rivera 2018 argue that religion (of beneficiaries or organizations) also 
play an essential role in the relief supply chain, especially in religiously inspired societies. They further suggest that these factors should be considered among success factors when discussing the humanitarian supply chain. Despite the handful of studies indicating to explore this area further, not much attention has been paid to this suggestion in humanitarian literature. According to Paulson and Menjivar 2012, it is important to study religion in the disaster relief context for two reasons. First, situations like disasters exploit social phenomena and uncover hidden sociological outlines. Second, among people and societies, religious organizations have significant importance and they often play a pivotal role in mobilizing funds and spiritual relief to the beneficiaries severely affected by disasters. He further adds, apart from the role and influence of religious institutions, victims associate themselves with a religious identity, which provides them spiritual and mental relief.

Nonetheless, as discussed by Celik et al. 2014 in a disaster situation, due to insufficient resources, it is crucial for all humanitarian organizations (HOs) or other actors involved in relief operation to develop their performances in order to respond to a disaster effectively. Moreover, as HOs are expanding their operations globally, it is also adding to their challenges, like high urgency, uncertainty, lack of resources, and local infrastructure, which can make already challenging task even more daunting (Jamison M. Day et al. 2012; Martinez et al. 2011). The 2004 Asian Tsunami might be an excellent example to understand the impact of the global humanitarian relief operation; in this case, over 700 nongovernmental organizations (NGOs) from 40 countries (including the aid from the governments from these countries) assisted the victims (Balcik et al. 2010). However, as we discuss to improve the effectiveness of the humanitarian operation, it is not possible to create an ideal system for such an unideal situation like sudden onset disaster, which could happen anywhere and anytime. Therefore, as discussed by Yadav and Barve 2015, there is a need to fragment the management processes into factors in order to enable and systematically manage certain activities during the disaster relief operation. That is how responsible individuals would be able to improve the disaster management process by focusing on significantly important factors or priority factors. The concept of critical factors roots from commercial supply chain context and it has been extensively studied in the commercial setting but its application has rarely been witnessed in the humanitarian sector (Kabra and Ramesh 2015b).

Therefore, considering the importance of studying these factors to improve relief supply chain's effectiveness and efficiency, this paper aims at identifying and prioritizing such important factors which we refer to as critical success factors (CSF). In humanitarian literature, these factors are commonly referred to as either CSF (Pettit and Beresford 2009; Yadav and Barve 2015, 2018) or key success factors (KSF) (Oloruntoba 2010). Through this paper, we aim to develop and explore not only the significance and importance of the selected critical internal and external success factors of the humanitarian supply chain (Martinez et al. 2011) but also examine and explore the understudied area of religion in humanitarian settings (Paulson and Menjivar 2012), and we do so by identifying the differences in opinions of faith-based organizations (FBOs) and non-faith based organizations (NFBOs) about the selected CSFs. Moreover, we further examine within FBOs the differences between Islamic and Christian relief organizations. We also examine if the religion of beneficiaries and religious affiliation of organizations play any role in the relief operation. Thus it leads to the research questions designed for this study:

1. Which internal and external CSFs are significantly important for the disaster relief organizations in their supply chain?

2. What are the differences in importance and prioritization of internal, external CSFs in the humanitarian supply chain for faith-based, and NFBOs relief organizations?

3. What are the differences in importance and prioritization of internal and external CSFs in the humanitarian supply chain for Christian and Islamic relief organizations?

\section{Literature review}

In this section, we would briefly highlight the role and responsibilities of HOs and differentiate between faiths-based (Christian and Islamic Relief Organizations) and NFBOs relief organizations. Moreover, we briefly discuss the highlights of the humanitarian supply chain, and in last, we discuss in detail the selected internal and external critical success factors.

\section{Humanitarian relief organizations}

Sudden onset and offset disasters cause widespread disruptions, resulting in massive displacements of humans and collapsing socio-economic systems in affected countries (Dasaklis and Pappis 2018). They not only impact the normal functioning of the country or affected society but leave a long-lasting impact on those who are affected by these disasters in one way or the other (Kabra and Ramesh 2015a). These affected people, in the time of this misery, look for all the possible help they can get, and humanitarian or relief organizations (also referred as non-governmental organizations (NGOs) or international non-governmental organizations (INGOs)) make sure that the needs of these people are met at its earliest. Such organizations tend to follow the principles of humanity, neutrality, and impartiality, which allows them to help everyone in need anywhere despite their ethnic, religious, or political affiliation (Van Wassenhove 2017). A typical humanitarian operation aims at assisting victims in several ways, which includes but is not limited to, providing food, 
first aid and shelter, saving the wounded, properly disposing of corpses, allocating resources most efficiently, and restoring access to remote locations (Costa et al. 2012; Lijo et al. 2018).

Unarguably, the number of humanitarian emergencies is growing at an unprecedented rate, and with it, the complexity of these catastrophic events is inflating. Therefore, resulting in unparalleled pressure on agencies to deliver humanitarian aid in the most suitable yet cost-effective way (Rodon et al. 2012). There are several characteristics, which differentiate HOs from private or government aid organizations. However, on the grass-root level, they share a similar ideology of helping people in need (Sandwell 2011). The primary role of HOs is to assist victims of conflicts and natural disaster (Ferris 2005). Van Wassenhove 2017 defines the success of the humanitarian operation as "A successful humanitarian operation mitigates the urgent needs of a population with a sustainable reduction of their vulnerability in the shortest amount of time and with the least amount of resources."

According to Sridhar and Nagabhushanam 2008, it is imperative to understand that there are several types of humanitarian organizations (HOs) for instance HOs organized by the government, religious entities, corporate, or independent of any other body. For the last couple of decades, such organizations are gaining extraordinary attention, mainly due to the surge in the number of such organizations and also because of their involvement in almost every imaginable area of society. For instance, their agendas include but is not limited to humanitarian assistance, developmental aid, human rights, and environment protection, etc. (Jayasinghe 2007). However, as explained ahead, in this paper, we try to develop an understanding of faith-based (Islamic and Christian) and non-faith-based relief organizations, which are briefly explained in the following subsections.

\section{Faith-based relief organizations}

Involvement of FBOs in disaster response is not new. Benedetti 2006 and McLachlin et al. 2009 agree that such organizations have existed ever since the charitable work started taking the shape of HOs. Such organizations play a vital role in disaster or conflict by not only providing the mental and spiritual healing of the individuals but also by actively participating in the field to minimize the suffering by providing tangible aid and assistance (Clarke 2010; Rivera 2018). The term faithbased have varied understandings in different contexts, a broader perspective explains it as, all such organizations that engage in humanitarian work with religious motivation, or have strong links with religious organizations or share their values or objectives or take funding from them are considered faith-based HOs (Goldsmith et al. 2006; Jayasinghe 2007; Kraft and Smith 2019). However, Benedetti 2006 defines such organizations whose identity and mission are derived from the teaching of one or more religious or spiritual traditions and teachings are considered FBOs and such organizations are fundamentally very different from secular organizations. Therefore, they might be resistant in working together with their secular counterparts due to the fear of compromising on their religious values (Goldsmith et al. 2006). He further added that unlike NFBOs, FBOs have more centralized decision making, and they may also rely on the advice from their spiritual leader. Moreover, FBOs mostly rely on their religiously motivated workers and volunteers for official and fieldwork. To sum up, there are two main traits of FBOs which sets them apart from their nonreligious counterpart; first, they are motivated by their faith and second, they have a constituency which is broader than humanitarian concerns (Ferris 2005).

FBOs have proven to be more effective in religiously motivated societies, where such organizations are not only trusted because of cultural or religious similarities they share with beneficiaries but they also possess or have immediate access to resources, such as human resource, donors and facilities, etc. Therefore, in the time of need, such organizations provide a wide variety of direct services to the beneficiaries more effectively compared to international HOs and this is the reason that recently international $\mathrm{HOs}$ are making stronger ties with local FBOs (Ferris 2005; Goldsmith et al. 2006; Kraft and Smith 2019; Rivera 2018; Samuels 2016; Stajura et al. 2012). Moreover, people also call for support and help from similar faith organizations in the time of distress. Okkenhaug 2015 recalls and examines one such incident from the past 1918-1920, where Christian Armenian women and children were forcefully held captive in Muslim households, and it gained the attention of Christian HOs and other actors in the west, and they rescued them eventually. Similarly, most recent example of Syrian refugee crises witnessed an overwhelming role of both Islamic and Christian organizations in order to facilitate the refugees and build local networks and collaborations with local governments and other actors (Kraft and Smith 2019).

However, association with faith could also have its consequences, as the religious affiliation of a particular organization can discourage donors from contributing if they do not belong to the similar faith group. Differences in religious affiliation of donor and relief organization can make donors less charitable toward such recipients (Tremblay-Boire and Prakash 2019). Moreover, uncertainty and suspicion of not using the funds provided by international donors and not adhering to humanitarian principles of impartiality by FBOs also discourage the funding to such organizations (Kraft and Smith 2019). Furthermore, literature also suggests that FBOs also face discriminations at the hands of the local government if they do not share similar religious values (Grung 2018). In this paper, we would compare only Christian and Islam faithbased HOs as these are the two most practiced religions in the world. Christianity with a roughly estimated population of around 2.17 Billion believers and Islamic population of 
around 1.59 Billion, which consecutively constitute around $31 \%$ and $23 \%$ of the world's total population (Hackett and McClendon 2017).

\section{Christian relief organizations}

The rise in the number of HOs connects back to 1860 to the 1960s "missionary phase" of Christian individuals and organizations whose prime objective was to build the Christian faith by funding aid and development initiatives (Fountain et al. 2004). Benedetti 2006 explains: Christian organizations are mostly divided into the Protestants and the Catholics. However, omnipresence varies considerably across these organizations. Even if the organizations affiliate themselves with Christianity, they are still composed of the staff and members which are non-practicing Christians. Many of these organizations, similar to NFBOs, are multinational, but their organizational ideology varies in representation, some belief in representing the totality of believers of a particular faith and other believe in the multi-dimensional spirit and claim to represent Christian philosophy. Moreover, similar to Islamic believes, practicing Christians also refer to disaster as "Act of God." Thus, in such a situation, they seek help from the organizations preferably belonging to the Christianity faith, and on an operational level to meet the needs of these victims, these organizations get their funding from either government or voluntary donations which keeps them up and running (Fountain et al. 2004).

\section{Islamic relief organizations}

Samuels 2016 suggests that it is vital to understand the historical background of the formation of any religious relief organization in order to understand its operations and activities and Hackett and McClendon 2017 briefly explain the background of Islamic relief organizations in their paper; they noted that Islamic FBOs are relatively younger in age than Christian organizations. Most of the Islamic relief organizations came into existence once after each of the four significant events in history, which affected the Muslim population. (1) 1979's Soviet invasion of Afghanistan, (2) the Iranian revolution, (3) the Israeli invasion in Lebanon, and (4) the defeat of USSR in 1989. These four mega-events paved the path for Islamic relief organizations. However, there has been an overall surge of HOs since the 1970s. The types of Islamic relief organizations vary just like their Christian counterpart. It has also been observed that some of the Islamic organizations exploit the humanitarian grounds for preaching purposes too, which makes them relatively different than Christian organizations. In the beginning, for Islamic organizations, religion was very important even for their members and staff; however, as they popularized, they started employing the people who were looking for jobs, and they started hiring them without focusing much in their religious affiliation. However, in contrast with the presence of Christian organizations in almost all countries, Islamic organizations are mostly present in those countries where Islamic presence is robust, but there is no significant difference in the organization structure of Islam-based, Christian, and secular organizations, but Islamic organizations are more centralized compared to Christian organizations. Furthermore, Islam, like Christianity, also teaches to help the less fortunate in the society or community with regular donations (Tremblay-Boire and Prakash 2019). However, when distributing in-cash donations "referred to as Zakat" (one of the pillars in of Islam), most of Islamic NGOs prioritize in aiding Muslims. Although there is a condition available to give incash donations to a traveler in need, however, only some genuinely global Islam FBOs follow it (e.g., Islamic Relief). Unlike Christian-inspired organizations, Islam-based organizations gather sizable donations mostly because of the similar principle discussed above (Benedetti 2006). Anyhow, significant donors like United Nations, European Union, and the World Bank put restrictions on Islamic relief organizations in the Islamic world to adhere to the neoliberal democratization doctrine, which stands on the pillars of civil society, privatization, and good governance in order to be eligible to gain funding (De Cordier 2009). Moreover, some donors' suspicion about the activities of the organization and undocumented usage of money also stops them from providing funding to specific Islamic faith-based HOs, and such restrictions have often been observed after 9/11 incident (Arif 2008).

\section{Non-faith-based relief organizations}

Several researchers refer to NFBOs as secular organizations and agree that they are not much different from their religious counterpart. Apart from that, these organizations deal with beneficiaries and provide assistance aid and relief purely on humanitarian grounds and not with some missionary zeal (Benedetti 2006; Ferris 2005; Goldsmith et al. 2006). Goldsmith et al. 2006 further noted that these organizations tend to have higher organizational capacities compared to FBOs. Generally, when humanitarian relief organizations (HROs) are not affiliated with any religion, it is considered secular or NFBO, thus the reader can refer to the explanation of "HROs" in the subsection above to understand the goals, motivation, and working of these organizations.

\section{Humanitarian supply chain}

Humanitarian supply chains are almost 15 years behind the commercial supply chains (Van Wassenhove 2017). Better late than never, finally, the humanitarian supply chains are catching up with their commercial counterparts. They have started borrowing several different traits from the commercial supply chain. Presently, both share similar activities like 
preparation, planning, procurement, transportation, storage tracking, and customs clearance. However, in principle, humanitarian supply chain focuses completely on humanitarian actions, which differentiate it from its commercial counterpart (Costa et al. 2012; da Costa et al. 2014; Lijo et al. 2018). A practical, efficient, and timely supply chain management is directly proportional to the success of disaster relief operation, the speed with which medicine, food, shelter, and water is provided to the beneficiaries can be the difference between life and death (Abidi et al. 2014).

However, there is no particular supply chain when it comes to humanitarian settings, and it adapts according to different types of disasters (Eriksson and Karlsson 2017). The donors become customers, and HOs sell them ideas instead of products, and the objectives become humanitarian instead of economic gain (McLachlin et al. 2009). Therefore, the challenges of the humanitarian supply chain are also different from the commercial supply chain. Kabra et al. 2015 highlighted certain factors like "uncertainty about occurrence of a disaster, irregularity in demand and less time to deliver the relief material with the constraint of lack of resources" sets humanitarian supply chain apart from its commercial counterpart. However, from a holistic perspective, humanitarian supply chain management during relief operations involves managing all of the stakeholders on strategical, tactical, and operational levels in order to facilitate the beneficiaries as effectively and efficiently as possible. Nonetheless, the ultimate goal of the humanitarian supply chain is to deliver donated supplies to the affected areas in the shortest possible period most effectively and efficiently (Ngwenya and Naude 2016).

\section{Critical success factors}

The idea of studying critical success factors (CSFs) also knows as key success factors (KSFs) to improve the effectiveness and efficiency of organizations or its processes is not new. This concept has widely been applied in different circumstances in supply chain management, operational management, organizational management, and enterprise resource management (Celik et al. 2014). However, the academic evidence shows that CSFs' roots are buried deep into the organizational studies in management. CSFs are such business areas or processes, when they work in complete harmony, will guarantee successful competitive performance for an organization. According to Oloruntoba (2010), "CSFs are the conditions, characteristics, or variables that when properly cultivated, sustained, maintained or managed can have a significant impact on the success of a company or its endeavor." However, when compared to their commercial counterpart, CSF in humanitarian settings are not studied or identified to increase the profits but are examined to provide effective and efficient humanitarian services and save time. Therefore, it is essential to define CSFs to avoid or minimize the risk of failure in humanitarian operations (Eriksson and Karlsson 2017; Pettit and Beresford 2009).

\section{External factors}

Table 1 below summarizes all such external factors, which are shortlisted for this study. For this study, we define external factors as all such factors on which relief organizations have no direct influence or control.

Table 1 External factors selected for this study

\begin{tabular}{|c|c|c|}
\hline External factors & Grouped factors & References \\
\hline Religion of beneficiaries & - & (Benedetti 2006; Paulson and Menjivar 2012) \\
\hline Culture of beneficiaries & Incl. traditions, norms, language, food, and dressing & $\begin{array}{l}\text { (Balcik et al. 2010; Benedetti 2006; Dale and } \\
\text { Dulaimi 2016; Rodon et al. 2012) }\end{array}$ \\
\hline Donor restrictions and influence & - & $\begin{array}{l}\text { (Burkart et al. 2016; Costa et al. 2012; } \\
\text { Martinez et al. 2011; Ngwenya and } \\
\text { Naude 2016; Sandwell 2011; } \\
\text { Scholten et al. 2010) (Azmat and Kummer 2019) }\end{array}$ \\
\hline $\begin{array}{l}\text { Blocked supply lines and rugged } \\
\text { topography }\end{array}$ & $\begin{array}{l}\text { Incl. lack of transport infrastructure, delays in custom } \\
\text { and clearance and blockade due to extreme weather } \\
\text { conditions }\end{array}$ & $\begin{array}{l}\text { (Costa et al. 2012; Dube et al. 2016; } \\
\text { Martinez et al. 2011; Moshtari and } \\
\text { Gonçalves 2016; Ngwenya and } \\
\text { Naude 2016; Scholten et al. 2010; } \\
\text { Yadav and Barve 2015, 2018) }\end{array}$ \\
\hline Host government access and policies & - & $\begin{array}{l}\text { (Dasaklis and Pappis 2018; Dube et al. 2016; } \\
\text { Sridhar and Nagabhushanam, 2008; } \\
\text { Yadav and Barve 2015, 2018) }\end{array}$ \\
\hline Limited resources & $\begin{array}{l}\text { Incl. limited funding, supplies, human resource, } \\
\text { transport vehicles, capacities, etc. }\end{array}$ & $\begin{array}{l}\text { (Balcik et al. 2010; Costa et al. 2012; } \\
\text { Dasaklis and Pappis 2018; Eriksson and } \\
\text { Karlsson 2017; Martinez et al. 2011; } \\
\text { Ngwenya and Naude 2016) (Azmat and Kummer 2019) }\end{array}$ \\
\hline
\end{tabular}




\section{Religion of beneficiaries}

According to Paulson and Menjivar (2012), religion plays an essential role in the lives of those who belong to one or the other form of religion. Religious victims of the disaster strongly associate themselves with their religious believes as it provides spiritual and mental relief.

\section{Culture of beneficiaries (including traditions, norms, language, food and dressing)}

According to Dale and Dulaimi (2016), to maximize the chances of mutually beneficial outcomes during a relief operation, are only possible when the project managers in NGOs or INGOs can build an association with people from different cultural backgrounds, whom they intend to work with or work for. They further added that having the cultural knowledge and information is beneficial for such organizations as it enables their workers to understand social codes and body language of the beneficiaries. Without such knowledge and information, a relief organization finds it challenging to interpret and understand what a local team member or a beneficiary is thinking. Not having ample cultural knowledge could lead to wastage of resources and time or even project ideas, which, might not be beneficial or needed by that community at that time. According to Rodon et al. (2012), humanitarian literature suggests that cultural differences can affect the effectiveness of humanitarian aid by causing disruptions in operational coordination. They also mentioned that previous literature mainly focuses on the differences in the organizational culture of the aid organizations. Whereas, there is an imminent need for understating the cultural differences between beneficiaries and those delivering aid.

The Médecins Sans Frontières' (MSF) case of the Somalian cholera epidemic in 1994 is a perfect example to understand how cultural differences between relief organizations and beneficiaries can sabotage humanitarian operations. MSF placed hygienic and precautionary measures for the safe burial of the dead bodies to avoid spreading epidemic from the infected corpses, and this did not allow the locals to say the last goodbye to their loved ones in a traditional way. This action resulted in violence against MSF personnel and led the local community to abandon the use of the cholera epidemic center which was formed for the treatment of cholera, gave advice to the health authorities, and performed "safe" burials. This example shows how a failure to pay attention to the local cultural systems reduced the effectiveness of the humanitarian response to the cholera epidemic in Somalia (Rodon et al. 2012).

\section{Donor restrictions/influence}

Donors are one of the most integral parts of the humanitarian supply chain, and they contribute billions of dollars for humanitarian assistance, for instance, in 2015 alone, a total of 28.0 billion US dollars were contributed by different Governments, EU, and private donors combined (Burkart et al. 2016). Therefore, the majority of relief organizations mostly rely solely on the funding provided by different donors and cannot initiate the relief process until they have received donations. Donors, on the other hand, are not bound to fund any disaster, however, even if they provide funding, relief operation they can still opt to exit the collaboration if the relief organization does not meet the obligations described in the contract with donors. To sponsor a relief operation, most of the donors demands accountability, transparency, and value for money, which is becoming more and more difficult as the complexity of such disasters is increasing (da Costa et al. 2014; Scholten et al. 2010). In many cases, donations are issued to be used for intended purpose only (earmarked donations), which limits the freedom of using the funds as deemed best by the relief organizations resulting in affecting the operational activities and freedom of a relief organization (Balcik et al. 2010; Besiou et al. 2011; Burkart et al. 2016; da Costa et al. 2014).

\section{Host government access/policies (including customs issues)}

According to Dube et al. (2016) in a disastrous situation, it is the responsibility of the host government to coordinate and facilitate the actors involved in humanitarian relief efforts. However, these relief efforts can easily be destroyed by the political tension among different players involved in a relief operation. Therefore, the political context in which a disaster occurs could be very critical for those aid organizations (Dasaklis and Pappis 2018; Dube et al. 2016). However, they also suggest that for a successful relief campaign, the involvement of local government is of extreme importance along with several other key actors. The government plays the role of the central authority in relief operations. Therefore, facilitation services provided by the host government could dramatically enhance the effectiveness and efficiency of the relief operation (Kabra and Ramesh 2015b). The governments also provide financial assistance to relief organizations; however, some organizations avoid taking such funds as they directly or indirectly oblige them to work with the government. Such NGOs which usually rely on are motivated by the hefty amount of grants provided by governments do not sustain in the long run and perish over time. However, some projects could merely not complete without the government's support (Sridhar and Nagabhushanam 2008).

Blocked supply lines and rugged topography (including lack of transport infrastructure, delays in custom and clearance, and blockade due to extreme weather conditions)

According to Balcik et al. (2010) and Ngwenya and Naude (2016), transportation is considered the most significant and most challenging part of the disaster relief operation. After a disaster strikes, it leaves infrastructure damaged or 
thoroughly washed out, most of the supply lines blocked, transportation resources become scares and above all, transporting a bulk load of supplies to beneficiaries in the affected area makes this already difficult task even more challenging. These topographical challenges constrain the use of already scarce resources. They further added that complex topographical characteristics of affected areas, like mountainous terrain or extremely harsh weather, could easily affect the relief operation. Which results in a delay to provide not only the aid and supplies (for example, remote areas may only be reachable by small trucks or helicopters, whereas larger vehicles may only be used for nearby areas) but also to assess the magnitude of catastrophe (Balcik et al. 2010).

\section{Limited resources (including limited funding, supplies, human resource, transport vehicles, capacities, etc.)}

Due to the disaster-related uncertainties like its location, time, and intensity, it is nearly impossible to match demand and supply both in pre- and post-disaster relief activities. Moreover, the lack of supporting resources like financial, human, technological, and informational adds to the challenges HOs face during the relief operation (Balcik et al. 2010). Moreover, Ngwenya and Naude (2016) and Pettit and Beresford (2009) explain that capacities also limit the humanitarian relief efforts; he defines capacity as "the ability of the organization to conduct operations of different volumes, in various areas, at different times and to provide a diverse range of services and relief supplies". Therefore, to effectively respond to a disaster with limited or insufficient resources, it is important for all relief actors to develop their capabilities and capacities (Celik et al. 2014; Eriksson and Karlsson 2017). One other mostly discussed shortage of resource is transported vehicles. It is nearly impossible for NGOs or INGOs to own and operate fleet vehicles, as it is neither financially feasible nor practical to carry the fleet of vehicles from one operation to other or to sell and buy new ones each time. Therefore, this kind of agencies typically rents local vehicles and drivers. Thus, at the time of disaster, demand for such vehicles increase dramatically, and they become scares resulting in inflated rental costs of the vehicles, if still available (Balcik et al. 2010).

\section{Internal factors}

Table 2 below summarizes all such internal factors, which are shortlisted for this study. For this study, we define internal factors as all such factors on which relief organizations have direct influence or control.

\section{Religious affiliation of the organization}

Organization's religious values and norms can facilitate the coordination and cooperation among locals and relief organizations (Benedetti 2006; Paulson and Menjivar 2012). However, there has been discrimination cases reported against the local government, which does not necessarily support the operations of different FBOs in the local community, but these cases might be exceptions and have not been addressed widely (Grung 2018). On the other hand, an advantage of the religious affiliation of organizations can help obtain funds from the donors, both local and international, who follow similar faith (Fountain et al. 2004).

\section{Information collection (including needs assessment, first information about disaster, and information on available resources)}

According to Moshtari and Gonçalves (2016) and Balcik et al. (2010), the first hand reliable, adequate, and timely information about the disaster location, its intensity, the damage it caused to infrastructure, and the number of the affected population is vital for the success of relief operation. Sridhar and Nagabhushanam (2008) and Costa et al. (2012) adds, for any HOs to implement their relief programs successfully, it is imperative to understand the needs of the beneficiaries. Whereas, some researchers also add that factors like knowledge and information about the developmental needs of the community are also critical for the success of relief operation (Dale and Dulaimi 2016; Moshtari and Gonçalves 2016). If there is no or inaccurate information on the needs of the beneficiaries provided by the affected governments and local HOs, the supplies are transferred to the affected areas with the hope that they will be adequate to meet the needs of the victims. However, it leaves the chance of severely hampering the relief operation in a case if the provided supplies are insufficient or were not needed at all (Ngwenya and Naude 2016).

\section{Organization's culture}

Culture of HOs heavily influences its management. Every organization tries to adopt the best methods and practices, which suits the organization's culture and the situation (Rodon et al. 2012; Sridhar and Nagabhushanam 2008). They also suggest that NGOs survival and success heavily relies on their culture and values, which bonds all the volunteers who work for these NGOs. Moreover, Sandwell (2011) and Kabra et al. (2015) also agrees that the culture of such organizations is built on their values and morals. These standards are reflected in their work, which helps them attract people with a similar philosophy. His research findings also suggest that the cultural characteristics of such organizations are similar to direct actions, which can make a difference. Therefore, most of the relief organizations stand on the shoulders of people who are "pragmatic in nature, risk takers and achievers".

\section{Organization's structure (including style of management and administration)}

According to Celik et al. (2014), HOs need to have a reasonable organizational structure where everyone is aware of their individual and collective responsibilities in order to have the substantial influence on the overall system. 
Table 2 Internal factors selected for this study

\begin{tabular}{|c|c|c|}
\hline Internal factors & Grouped factors & References \\
\hline $\begin{array}{l}\text { Religious affiliation of } \\
\text { organization }\end{array}$ & - & (Benedetti 2006; Grung 2018) \\
\hline Information Collection & $\begin{array}{l}\text { Incl. needs assessment, first information } \\
\text { about disaster and information on } \\
\text { available resources }\end{array}$ & $\begin{array}{l}\text { (Balcik et al. 2010; Costa et al. 2012; Dale } \\
\text { and Dulaimi 2016; Martinez et al. 2011; } \\
\text { Moshtari and Gonçalves 2016; Ngwenya } \\
\text { and Naude, 2016; Pettit and Beresford 2009; } \\
\text { Sridhar and Nagabhushanam 2008; Yadav } \\
\text { and Barve 2015) (Azmat and Kummer 2019) }\end{array}$ \\
\hline $\begin{array}{l}\text { Willingness for coordination } \\
\text { and collaboration }\end{array}$ & - & $\begin{array}{l}\text { (Balcik et al. 2010; Bealt et al. 2016; Celik et al. 2014; } \\
\text { Costa et al. 2012; Dasaklis and Pappis 2018; } \\
\text { Lijo et al. 2018; McLachlin and Larson 2011; } \\
\text { Moshtari and Gonçalves 2016; Pettit and } \\
\text { Beresford 2009; Yadav and Barve 2015, 2018) (Azmat and Kummer 2019) }\end{array}$ \\
\hline Organization's structure & Incl. style of management and administration & $\begin{array}{l}\text { (Balcik et al. 2010; Celik et al. 2014; Costa et al. 2012; } \\
\text { Dasaklis and Pappis 2018; Sridhar and Nagabhushanam 2008) }\end{array}$ \\
\hline Organization's culture & - & $\begin{array}{l}\text { (Benedetti 2006; Kabra et al. 2015; Rodon et al. 2012; } \\
\text { Sandwell 2011; Sridhar and Nagabhushanam 2008) }\end{array}$ \\
\hline Internal communication & $\begin{array}{l}\text { Incl. the flow of information, communication } \\
\text { technology and equipment }\end{array}$ & $\begin{array}{l}\text { (Benedetti 2006; Celik et al. 2014; Costa et al. 2012; } \\
\text { Eriksson and Karlsson 2017; Ngwenya and Naude 2016; } \\
\text { Pettit and Beresford 2009; Yadav and Barve 2015) }\end{array}$ \\
\hline
\end{tabular}

Moreover, Sridhar and Nagabhushanam (2008) explain that NGOs are different from business organizations. The HOs have a robust, informal but loosely tied structure, whereas in business organizations, there is a clear line of hierarchy. Relief organizations rely on the cross-functional links from the very beginning, whereas businesses have quite recently adopted it. HOs work with a vision rather than on working on functional lines, and most of their work is at the grassroot level as they mostly operate in the fields.

\section{Willingness for coordination and collaboration (including cost of coordination)}

Balcik et al. (2010) suggest that it is a common practice to use the words collaboration and coordination interchangeably among HOs. Therefore, for this study, we have selected both terms "coordination and collaboration" to explain the coordination factor. According to Bealt et al. (2016), a general lack of collaboration, coordination, and communication is commonly observed between different actors in disaster relief campaigns which often results in increased sufferings of the victims and overlapping or duplication of relief activities (Lijo et al. 2018). Moreover, existing literature also suggests that many factors contribute to such coordination difficulties in disaster relief. For instance, a large number of actors involved in already chaotic post-disaster relief environment, or lack of sufficient resources creating the atmosphere of urgency and involvement of several actors, which adds to failed collaboration efforts (Balcik et al. 2010; Kabra and Ramesh 2015a; Kabra et al. 2015; McLachlin and Larson 2011). However, for a successful relief campaign coordination among all of the key actors is extremely important, as lack of coordination is often one of the biggest causes of delays in the emergency relief (Dasaklis and Pappis 2018). Moreover, according to
Balcik et al. (2010), competition to get more donations during the early stages of disaster is one other reason which not only hinders the coordination among relief organizations but also severely affects the humanitarian mission. Moshtari and Gonçalves (2016) add that HOs not only compete for funds but also for media attention and local networks, which causes the hindrance in collaborative efforts.

A paper by Sandwell (2011) suggests that instead of competing for the funding, HOs should try to understand the greater edge collaboration could provide; these benefits include but are not limited to joint disaster preparedness strategies for vulnerable regions, collective bargaining, shared investment in technology, and developing a pool of shared knowledge/competencies among logisticians in the field. One other such factor that hinders coordination process is the cost of coordination. According to Balcik et al. (2010), coordination initiatives cost time and money for relief organizations, which also at times become one of the reasons HOs tend not to indulge in the greater coordination and collaboration phase. For instance, during the pre-disaster period, alliances at strategic and tactical levels can incur coordination costs, which may include but are not limited to salaries of staff and travel allowances to attend the coordination meeting. Whereas on an operational level, smaller organizations struggle with their resource, which may not allow them to allocate personnel to attend coordination meetings and provide relief simultaneously.

\section{Internal communication (including flow of information, communication technology, and equipment)}

The accuracy of the information and its flow within the organizations' supply chain are considered critical factors for a higher response efficiency (Ngwenya and Naude 2016). J. M. Day et al. (2009) also noted that better information flow in the 
humanitarian supply chain could dramatically increase not only the productivity of the supply chain but also help in the proper allocation of resources. However, in the modern era, technology provides a platform to relay this information up and downstream and assures the delivery of correct and reliable information faster than traditional ways of communication (Eriksson and Karlsson 2017). Therefore, nowadays, availability and proper utilization of communication tools, information technology, and equipment are critical for the success of relief operation (Kabra and Ramesh 2015b; Pettit and Beresford 2009).

\section{Methodology}

The research design adopts a two-stage strategy (Sandwell 2011). In the first stage, secondary data was collected using a thematic literature review technique leading to the development of an online 5-points Likert scale questionnaire (5 strongly agrees -1 strongly disagrees) (Azmat et al. 2019; Kabra et al. 2015; Meek et al. 2007). Whereas, in the second stage, as suggested by Banomyong et al. (2017) that there is an imminent need of surveys and empirical studies in order to increase the knowledge in the humanitarian field, we collected the primary data using the questionnaire designed in the first stage.

\section{Research framework}

Figure 1 below presents the framework designed for this study. It highlights all of the crucial steps from the collection of literature to answer the research questions.
First stage: thematic literature review

"The thematic analysis highlights the synthesis of the main outcomes from the extracted literature and gives us an overview of future research and practice and gaps in this field" (Abidi et al. 2014). Furthermore, it helps in understanding the concepts, analysis, and interpretation of the results of the subject matter (Leiras et al. 2014). Therefore, the first stage involves thematic literature review for the identification, sorting, and grouping of most repetitive critical success factors, as shown in Table 3 below. Apart from religion-related CSFs, all other relevant CSFs, which were discussed in more than four peer-reviewed academic papers published in recognized journals, were selected for this study. Whereas, the selection of "religion of beneficiaries" and "religious affiliation of organization" as a CSF was arbitrary.

Furthermore, authors used search queries to look for specific keywords in titles, for instance $(\mathrm{Ti}=$ ("NGO" OR "Non Gov" org" OR "Relief org" OR "INGO" OR "Humanitarian Org" OR "Disaster Relief" OR "Humanitarian" OR "Aid Agenc"*" OR "Humanitarian Logistic" OR "Emergency Relief" OR "Relief Chain") AND Ti = ("Key Success factor" OR "KSF" OR "Critical Success factor" OR "Success factor" OR "CSF" OR "SF")) were used for filtering the papers with CSFs of humanitarian relief. Whereas, queries like ( $\mathrm{Ti}=$ ("NGO" OR "Non Gov" org" OR "Relief org"” OR "INGO"” OR "Faith-based org" OR "Religious NGO*" OR "Humanitarian Org" OR "Disaster Relief" OR "Humanitarian" OR "Aid Agenc" manitarian Logistic" OR "Emergency Relief" OR "Relief

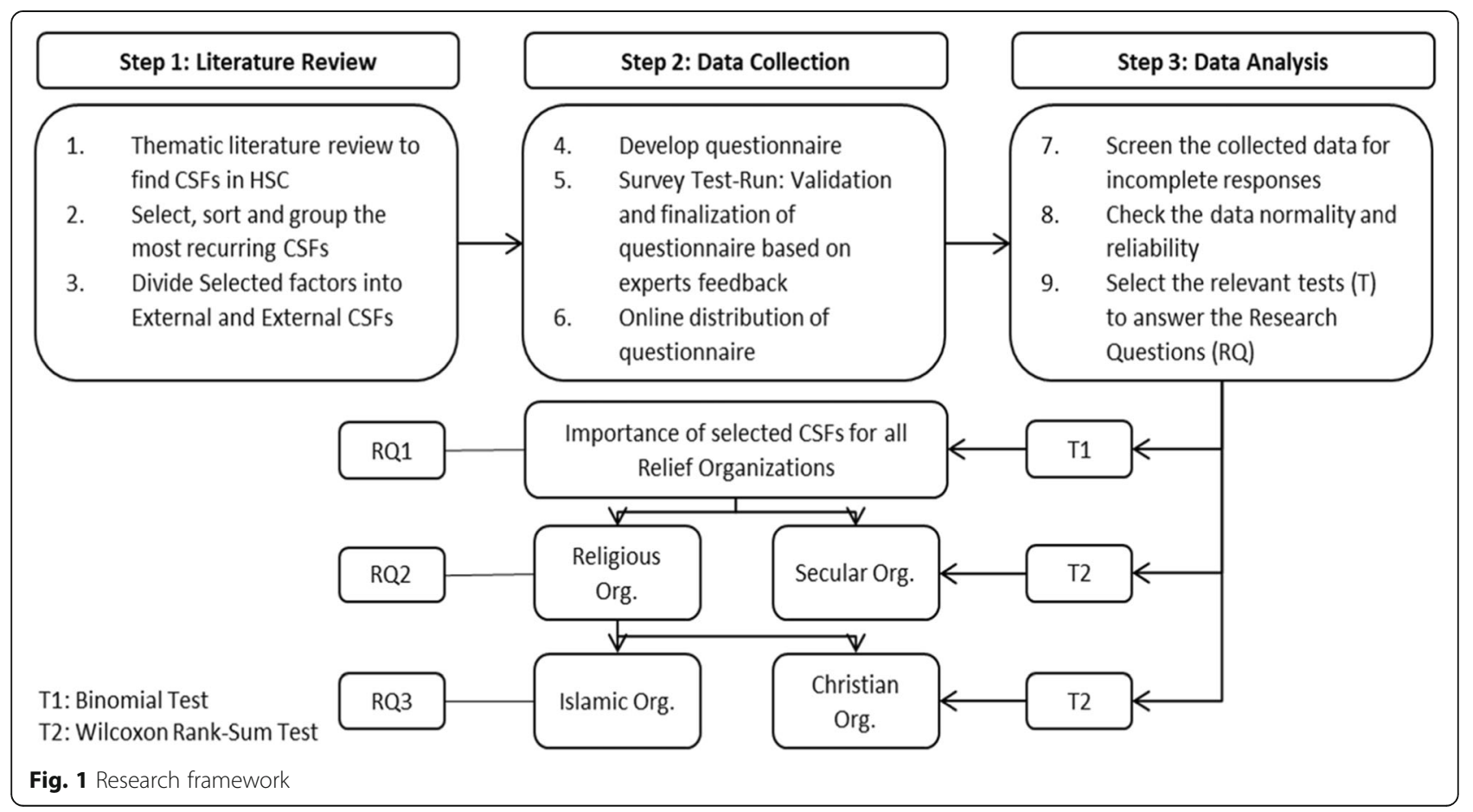


Table 3 Literature search results summary

\begin{tabular}{lllll}
\hline Database & Found articles & Relevant articles & Duplicate articles & Unique articles $^{\mathrm{a}}$ \\
\hline WOS & 31 & 24 & 5 & 19 \\
ProQuest & 26 & 22 & 12 & 10 \\
References from key articles & - & - & - & 12 \\
& & & Total & 41 \\
\hline
\end{tabular}

${ }^{\mathrm{a}}$ Thematic breakdown of found literature: CSF papers: 24; faith-based relief organizations: 17

Chain") AND Ti = ("Disaster" OR "Disaster Relief"” OR "Humanitarian relief" OR "relief" OR "Humanitarian Logistic" OR "Emergency Relief"” OR "Relief Chain*") AND $\mathrm{Ti}=$ ("Religion" " OR "faith" OR "Islam*" OR "Christian"” OR "atheist" OR "non-religious")) were used to filter the papers which discuss religion in humanitarian settings.

For maintaining the consistency and the quality of the literature review, only relevant peer-reviewed journal articles between 1990 and 2019 from academic databases of Web of Science (WOS) and ProQuest were targeted. These two databases were chosen because of convenience and ease of access. Moreover, these databases cover all the relevant journals and publishers, which publish articles in the humanitarian domain. Furthermore, some gray literature from a few websites was also explored for better understanding and deeper insights into the topic. Several refinement features of these databases were broadly used (multiple refinements of results following the context of specific articles, related documents search, etc.). References of key articles were also examined for identifying additional relevant literature (Dasaklis and Pappis 2018).

\section{Second stage: data collection}

Using online research methods to obtain data is gaining popularity among academic researchers. It promises higher and more diverse sample size, saves valuable time and resources, and provides convenient access at lower costs (Bealt et al. 2016). Therefore, the authors of the study used a similar approach in order to save time, cost, and gather more diverse sample size. The authors achieved this by using two approaches as discussed by Larson (2005); firstly, online surveys were distributed via email using the "Shot-gun" strategy, which allows the collection of a minimum acceptable number of responses, as cheaply as possible. Therefore, the authors gathered lists of NGOs from different online platforms like (Humanitarian Forums, Relief Forums, etc.) and started sending direct emails. However, during while sending direct emails, it was discovered that most of these email accounts were no longer active, which also indicate a high employee turnover rate in the humanitarian field (Besiou et al. 2011; Eriksson and Karlsson 2017). Approximately 800 emails were sent, out of which almost $60 \%$ remained undelivered and from the remaining $40 \%$ delivered emails, $60 \%$ did not respond to the email, 30\% said that they have never been involved in disaster relief operations, and only approximately $10 \% \quad(30$ organizations) filled out the questionnaire. Anyhow, this approach proved to be inefficient and time-consuming; even periodic reminders did not help in increasing the response rate.

Secondly, the authors adapted the "sharp-shooter" strategy, which involves using the limited survey administrative budget to gain the highest response rate by distributing a well-targeted mailing list. However, the authors achieved it free of cost by partnering with World Association of Nongovernmental Organizations (WANGO, 2000). Therefore, the online questionnaire was distributed worldwide to several HOs actively involved or have previously been involved in disaster relief operations. The questionnaire was distributed globally with the help of WANGO, who posted this survey in their monthly newsletter sent out to all member organizations in 120 countries. Initially, the responses were slow; however, after sending a reminder email to boost the response rate, we achieved the number of responses necessary to conclude the meaningful analysis.

Using both techniques, the authors could collect 91 responses. However, 19 of which were incomplete, therefore deemed unfit for analysis. This left authors with 72 complete responses fit for analysis. Incomplete survey responses are common in online data collection, and authors like Azmat et al. (2019) and Kabra et al. (2015) have also addressed similar issues with online surveys.

\section{Data analysis}

The data analysis is a subjective interpretation process that may encourage investigation of the empirical data more closely and hence enable a search for real meaning without introducing unfavorable preconceptions (Dale and Dulaimi 2016). However, for finding the right test for the statistical data analysis, it is essential to find if data meets the assumption of normal distribution. Therefore, the data normality test was conducted to see if the collected data is normally distributed or not. However, after testing the data using the KolmogorovSmirnov test, it was found that data does not meet the assumption of approximate normal distribution. Therefore, non-parametric tests were used for this research. The non-parametric test is widely used for studying the ranked order data (such as Likert scale or assessing preferences), where data receive a ranking but no numerical quantification. In this study, we designed a questionnaire 
to understand the preferences of the relief organizations for different internal and external factors, so we use two types of non-parametric tests, i.e., Wilcoxon rank sum test and binomial test (Corder and Foreman 2014).

First, in order to assess the level of agreement and significance of CSF by all respondents, binomial test was used. As discussed by Agresti and Coull (1998), the binomial tests show the possibility of occurrence of one of the two possible outcomes by measuring the deviation from the theoretical distribution of the data. Therefore, it was used to see the respondent's point of view on the significance of independent variables. The significance of each independent variable in all cases were tested with a cut-off point set at 3 , which means all respondents are divided into two groups. The first group are those whose opinions are greater than or equal to the cut-off point (3), from very strong to moderate intensity, and group 2 are those whose opinions are lesser than the cut-off value. The test proportion was set at $50 \%$. Secondly, as discussed by Haynes (2013) and Wilcoxon et al. (1970), Wilcoxon-rank sum test (aka Mann-Whitney $U$ test) was used to find the difference in the distribution of two independent variables. In this case, the faith-based and non-faith-based HOs were compared to answer the second research question, whereas Islamic and Christian relief organizations were compared to find the answer to the third research question.

\section{Data reliability test and descriptive statistics}

This section highlights the demographics of data, which also adds to the data credibility and reliability apart from testing the alpha of the collected data. Only gathering data is not sufficient to calculate meaningful results; the source of the data is also equally important. The significant part of the data was collected with the help of the World Association of Non-Governmental Organization (WANGO). A nonprofit association with thousands of member NGOs from all around the world.

\section{Data reliability test for the survey responses}

According to Tavakol and Dennick (2011), alpha is an important concept in the evaluation of data collected through questionnaires. Cronbach's alpha adds to the validity and accuracy to the interpretation of the data. Researchers agree that internal consistency should be determined before a test can be employed for analysis purposes to ensure validity. The acceptable values of alpha are between 0.70 and 0.95 (Bland and Altman 1997). Table 4 below shows the value of alpha for the responses of 12 factors under discussion, which is $0.750(75 \%)$-internal consistency, indicates that this data is fit for further analysis.

\section{Scope of operations and religious affiliation of the organizations}

The cross-tabulation (Table 5) below shows the breakdown of participating organizations concerning their
Table 4 Reliability statistics

\begin{tabular}{lc}
\hline Cronbach's alpha based on standardized items & N of items \\
\hline 750 & 12 \\
\hline
\end{tabular}

scope of operations (International, National, Regional, and Local) and their religious affiliation.

The collected data shows that out of 72 disaster relief organizations that participated in the survey, 24 affiliates themselves with Christianity, 22 with Islam, one with Hinduism, and 25 do not affiliate themselves with any religion. Which shows that the data has a right mix of organizations, and further analysis could be carried out in order to answer the research questions.

\section{Information about responding individuals}

The cross-tabulation Table 6 below shows the breakdown of responding individuals, with respect to their current position (title/designation) and experience in the number of years in humanitarian relief.

\section{Results and discussion}

This section analyzes the collected data in pursuit of answering the research questions developed for this study.

\section{Which CSFs are significantly important for HOs?}

We used the binomial test in order to assess the overall significance of both internal and external factors by all respondents, despite their religious affiliation. It is important to see an overall perspective of organizations participating or have previously participated in disaster relief operations. In the Table 7 below (group1 $\geq 3$ and group $2<3$ ), all such factors whose $P$ value (significance value) is less than $5 \%(0.000<0.05)$ are considered significant factors (Important) and the factor whose significance is less than $1 \% \quad(0.000<0.01)$ are considered extremely significant (very important). However, all such factors whose $P$ value (significance) is greater than $5 \%$ are considered insignificant. The table below shows that all the external factors selected in this study are extremely significant and can potentially disrupt the humanitarian supply chain during a relief process. It is also interesting that these results are in line with the literature of CSF discussed in "Literature review" section of this paper.

As shown in Table 8 (group1 $\geq 3$ and group $<3$ ) below, all tested internal CSF are extremely important for HOs; however, two of the internal factors have insignificant importance. Religious affiliation of the organization (.906> $0.05)$ and organization's culture $(0.724>0.05)$. The reason behind insignificant value for organizations religious affiliation could be that it does not matter for them what their religious affiliation is but when it is about providing aid and assistance to people in need, almost every organization believes in the principle of impartiality. Therefore, it is 
Table 5 Religious affiliation and scope of operations

\begin{tabular}{|c|c|c|c|c|c|}
\hline \multirow[b]{2}{*}{ Religious affiliation } & \multicolumn{5}{|c|}{ Scope of operations } \\
\hline & Local level & Regional/state level & National level & International level & Total \\
\hline Religious organizations & 3 & 6 & 13 & 25 & 47 \\
\hline Christianity & 0 & 2 & 5 & 17 & 24 \\
\hline Islam & 3 & 4 & 8 & 7 & 22 \\
\hline Hinduism & 0 & 0 & 0 & 1 & 1 \\
\hline Secular organizations & 1 & 2 & 4 & 18 & 25 \\
\hline Total & 4 & 8 & 17 & 43 & 72 \\
\hline
\end{tabular}

understandable that all organizations responding to this question disagree with this factor, as it does not cause any hindrance in the relief operation. However, organizations' culture is also insignificant though the literature suggests that organizations' culture might marginally hinder in the relief operation, as suggested by Sandwell (2011). Although, literature also suggests that beneficiaries cultural values matter more than the organization's culture (Rodon et al. 2012) (Dale and Dulaimi, 2016). Therefore, it is also understandable why participating organizations choose this as one of the insignificant factors. It is also worth considering that humanitarian aid is an ever-changing and evolving process, factors which were important a decade ago might not be as important in this time as they were in that time. Besides, it depends on the sample size of the previous studies, a smaller sample size from one or two countries, or the specific event might respond to similar questions differently. This study constitutes the results based on the responses from 72 disaster relief organizations worldwide. Such a diverse sample size is not commonly seen in previous studies, which analyze the CSFs in humanitarian settings.

What are the differences in importance and prioritization of internal, external CSFs in the humanitarian supply chain for faith-based, and NFBOs?

To understand which factors have significant importance for faith-based and NFBOs when compared with each other and how they prioritize these factors within the group, Wilcoxon rank-sign test was used.
Table 9 below shows that there is a statistically significant difference in assigning importance to the "religion of beneficiaries" and the "culture of beneficiaries" factors between faith-based and NFBOs. $P$ value is much smaller than $\alpha$ in both cases $(0.000<$ 0.05 and $0.008<0.05$ simultaneously); therefore, we have significant evidence that these two organizations treat these factor differently. However, the ranking based on the sum of the ranks tells us which organization gave more priority to which factor. In this case, "religion of beneficiaries" is more important for NFBOs than FBOs $(1351.5>1276.5)$; on the other hand, "culture of beneficiaries" is a more important factor for FBOs $(1500.5>1127.5)$. Whereas $P$ value of all other factors is higher than $\alpha$, therefore we have no significant evidence that the distributions of all other factors are different for faith-based and NFBOs. However, they are prioritized based on their sum of ranks, where higher the value of a sum of ranks higher the priority given by that particular organization to that particular factor when compared with its counterpart.

Similarly, in Table 10 below, the significance and priority ranking were measured for internal factors. The results show that $P$ value of all factors except "religious affiliation of organization" is higher than $\alpha$; therefore, we have no statistically significant evidence that there is a difference in distributions of these factors. However, $P$ value for "religious affiliation of

Table 6 Information about respondents' work experience in humanitarian settings

\begin{tabular}{|c|c|c|c|c|}
\hline \multirow[b]{2}{*}{ Experience in $\mathrm{RO}$} & \multicolumn{4}{|c|}{ Current Employment Level } \\
\hline & Top management & Managerial level & Field level & $\overline{\text { Total }}$ \\
\hline$>1$ (entry level) & 0 & 2 & 1 & 3 \\
\hline 1-3 (junior level) & 0 & 4 & 3 & 8 \\
\hline 3-5 (Mid-Level) & 2 & 13 & 6 & 20 \\
\hline 5-10 (Senior Level) & 9 & 11 & 2 & 21 \\
\hline < 10 (highly expr.) & 12 & 7 & 0 & 20 \\
\hline Total & 23 & 37 & 12 & 72 \\
\hline
\end{tabular}


Table 7 Binomial test for external factors

\begin{tabular}{|c|c|c|c|c|c|c|}
\hline & Category & N & Observed Prop. & Mean & SD & Exact sig. (two-tailed) \\
\hline \multirow[t]{2}{*}{ Religion of beneficiaries } & Group 1 & 52 & 0.72 & 2.53 & 1.54 & 0.000 \\
\hline & Group 2 & 20 & 0.28 & & & \\
\hline \multirow[t]{2}{*}{ Culture of beneficiaries } & Group 1 & 57 & 0.79 & 2.31 & 1.37 & 0.000 \\
\hline & Group 2 & 15 & 0.21 & & & \\
\hline \multirow[t]{2}{*}{ Donor restrictions/influence } & Group 1 & 69 & 0.96 & 1.75 & 0.82 & 0.000 \\
\hline & Group 2 & 3 & 0.04 & & & \\
\hline \multirow[t]{2}{*}{ Host government access/policies } & Group 1 & 70 & 0.97 & 1.69 & 0.73 & 0.000 \\
\hline & Group 2 & 2 & 0.03 & & & \\
\hline \multirow[t]{2}{*}{ Blocked supply lines and rugged topography } & Group 1 & 69 & 0.96 & 1.75 & 0.77 & 0.000 \\
\hline & Group 2 & 3 & 0.04 & & & \\
\hline Limited resources & Group 1 & 72 & 1 & 1.56 & 0.50 & 0.000 \\
\hline
\end{tabular}

organization" is smaller than $\alpha(0.001<0.05)$, which means there is a significant difference in the distribution of this factor between faith-based and NFBOs. Furthermore, the rank-sum test tells that FBOs give more importance to this factor compared to NFBOs $(1441>1187)$. However, while ranking factors within the group for FBOs, it is the least important factor when compared to the other factors in this group. However, it is considered one of the most critical factors when compared within the NFBOs group with the highest sum value of 1187 for this group.

Thus, it concludes that there is evidence of a statistically significant difference for some internal and external factors (as discussed above) between faith-based and NFBOs HOs. It is also observed that both organizations rank the priority of these factors differently. The higher rank score for some factor suggests which factor is more important for which type of organization when compared with one another and when compared with itself, this suggest the ranking for certain CSF within the group.
RQ3: what are the differences in importance and prioritization of CSFs in the humanitarian supply chain for Christian and Islamic HOs?

To answer the third research question, comparison of Christian and Islamic NGOs was performed using a similar technique, as discussed above. The results in Table 11 below indicate that there is a statistically significant difference in distributions for "culture of beneficiaries," "blocked supply lines and rugged topography," and "Host government access and policies" factors, where $P$ values are smaller than $\alpha(0.023<0.05,0.47<0.05$, and $0.040<0.05$ simultaneously). Moreover, the sum of the rank suggests that these three factors are more important for Christian organizations compared to Islamic organizations. Whereas, there is no statistically significant difference in distributions was found for the remaining external factors.

Results for the comparison between Islamic and Christian NGOs turned out to be statistically insignificant. In all cases, $P$ value is higher than $\alpha$, which tells there is no statistically significant difference in distributions of all

Table 8 Binomial test for internal factors

\begin{tabular}{|c|c|c|c|c|c|c|}
\hline & Category & $N$ & Observed prop. & Mean & SD & Exact sig. (two-tailed) \\
\hline \multirow[t]{2}{*}{ Information collection } & Group 1 & 70 & .97 & 1.72 & 0.70 & .000 \\
\hline & Group 2 & 2 & .03 & & & \\
\hline \multirow[t]{2}{*}{ Religious affiliation of the organization } & Group 1 & 37 & .51 & 3.31 & 1.36 & .906 \\
\hline & Group 2 & 35 & .49 & & & \\
\hline \multirow[t]{2}{*}{ Organization's culture } & Group 1 & 38 & .53 & 3.28 & 1.26 & .724 \\
\hline & Group 2 & 34 & .47 & & & \\
\hline \multirow[t]{2}{*}{ Organization's structure } & Group 1 & 67 & .93 & 2.10 & 0.84 & .000 \\
\hline & Group 2 & 5 & .07 & & & \\
\hline \multirow[t]{2}{*}{ Coordination and collaboration } & Group 1 & 67 & .93 & 2.06 & 0.93 & .000 \\
\hline & Group 2 & 5 & .07 & & & \\
\hline \multirow[t]{2}{*}{ Internal communication } & Group 1 & 65 & .90 & 2.17 & 0.92 & .000 \\
\hline & Group 2 & 7 & .10 & & & \\
\hline
\end{tabular}


Table 9 Wilcoxon rank-sum test for external factors (faith-based and NFBOs)

\begin{tabular}{llllll}
\hline External factors & W-Rank affiliated & W-Rank un-affiliated & $P$ value & Priority rank affiliated & Priority rank un-affiliated \\
\hline Religion of beneficiaries & 1276.5 & 1351.5 & 0.000 & 6 & 1 \\
Culture of beneficiaries & 1500.5 & 1127.5 & 0.008 & 5 & 2 \\
Donor restrictions and influence & 1581.5 & 1046.5 & 0.080 & 4 & 3 \\
Blocked supply lines and rugged topography & 1629.5 & 998.5 & 0.248 & 3 & 4 \\
Host government access and policies & 1714.5 & 913.5 & 0.990 & 2 & 5 \\
Limited resources & 1819.5 & 808.5 & 0.153 & 1 & 6 \\
\hline
\end{tabular}

internal factors; however, as shown in Table 12 below, based on the sum of the rank values, we can still assign priority ranks to each factor based on the higher to lower values corresponding from higher to lower ranks.

Thus, it concludes that there is a statistically significant difference in the distributions of some of the external factors where $P$ value is smaller than $\alpha$. However, there are no statistically significant differences in distributions of external factors. Which means both organizations have a similar approach toward assessing these factors in the humanitarian supply chain.

\section{Conclusion, limitations, and future directions}

This paper had a trifold objective, (1) to identify, filter, sort, and group the most discussed critical success factors in existing humanitarian literature; (2) to find out the importance of these factors for humanitarian relief organizations; and (3) to see whether there exists a difference in the importance of these factors for faith-based and non-faithbased relief organizations. We also divided the faith-based organizations into two more groups of Islamic and Christian organizations to see the differences between them.

For the first part, we assessed the existing humanitarian literature and gathered the most recurring critical success factors in the literature, which are explained above. We found out that several researchers pressed extraordinary stress on factors like donor restrictions, transport and logistics-related issues, importance of information collection, and most importantly, on collaboration and coordination within and among organizations. The results of the first research question of our study also confirm that all these limelight factors have extremely significant importance for disaster relief organizations. These factors, when appropriately nurtured, have the potential to significantly improve the effectiveness and efficiency of the humanitarian supply chain in the response phase. However, the results indicate that not all of the factors discussed in the literature carry significant importance. For instance, the literature suggested that the organization's culture and religious affiliation of the organizations might hamper the success of relief operation. The results of our study negate this phenomenon. The organization's culture and its religious affiliation might be valuable for some specific cases and in some specific areas, but the general population thinks otherwise.

Second, the results of the survey show that for nonreligious (secular) organizations, the religion of the beneficiaries, the culture of the beneficiaries, and the internal communication matters. Whereas, for faith-based organizations, these factors are not equally important. Authors of this study assessed it in one of the surprising discovery through this research. Non-religious organizations when dealing with religiously motivated beneficiaries come across challenges and hurdles that faith-based organizations could easily avoid especially on the local, regional and national levels, as they mostly consist of the trusted members of the society and beneficiaries tend to trust them more than secular organizations if they belong to the similar faith group. FBOs also have an edge, as they are well aware of the local culture; moreover, their centralized structure is also advantageous in such situations, as it allows an uninterrupted flow of information and this gives them an upper hand on secular organizations. Somewhat similar thoughts have also been noted by Ferris 2005, Goldsmith et al. 2006, Kraft and Smith 2019, Rivera 2018, Samuels 2016, and Stajura et al. 2012, where they explain how and why certain societies trust more on faith-based organizations. Whereas, the example of MSF in Somalia explains how differences in cultural values of the

Table 10 Wilcoxon rank-sum test for internal factors (faith-based and NFBOs)

\begin{tabular}{llllll}
\hline Internal factors & W-Rank affiliated & W-Rank un-affiliated & $P$ value & Priority rank affiliated & Priority rank un-affiliated \\
\hline Religious affiliation of the organization & 1441.0 & 1187.0 & 0.001 & 6 & 1 \\
Internal communication & 1582.5 & 1045.5 & 0.004 & 5 & 2 \\
Organization's culture & 1613.0 & 1015.0 & 0.209 & 4 & 3 \\
Coordination and collaboration & 1669.0 & 959.0 & 0.524 & 3 & 4 \\
Organization's structure & 1679.0 & 949.0 & 0.614 & 2 & 5 \\
Information collection & 1761.5 & 866.5 & 0.527 & 1 & 6 \\
\hline
\end{tabular}


Table 11 Wilcoxon rank-sum test for external factors (Christian and Islamic relief organizations)

\begin{tabular}{lllllc}
\hline External Factors & W-rank Christianity & W-rank Islam & $P$ value & Priority rank Christianity & Priority rank Islam \\
\hline Culture of beneficiaries & 660.5 & 420.5 & 0.023 & 1 & 6 \\
Blocked supply lines and Rugged topography & 643.0 & 438.0 & 0.047 & 2 & 5 \\
Host government access and policies & 640.0 & 441.0 & 0.040 & 3 & 4 \\
Donor restrictions and influence & 638.5 & 442.5 & 0.068 & 4 & 3 \\
Religion of beneficiaries & 624.5 & 456.5 & 0.145 & 5 & 2 \\
Limited resources & 504.0 & 577.0 & 0.119 & 6 & 1 \\
\hline
\end{tabular}

society and relief organization could be the reason for the failure of relief operation (Rodon et al. 2012). However, the results show us that there is no statistically significant difference in the importance of other factors, and all of the organizations consider those factors as critical factors. Still, they prioritize them within the group differently, which itself might be a debatable topic if we should rank these factors or not. However, there is no absolute way of quantifying the qualitative things like these factors. Few researchers have tried different fuzzy techniques and approaches to quantify these values; nonetheless, those approaches are arguable (Celik et al. 2014; Kabra and Ramesh 2015a, 2015b). Therefore, we tried a new approach to ranking these factors by merely using a statistical method.

Third and last, the results of the study tell us that there is a statistically significant difference in the opinions of Islamic and Christian organizations for three out of the 12 factors under study. Christian organizations seem to believe that culture of beneficiaries, blocked supply lines and rugged topography, and host government access and policies are three most important factor (consecutively). Whereas, Islamic organizations neither rate nor rank them as statistically significant factors. However, all other factors in this study are equally important for Islamic and Christian organizations when compared with each other, but surprisingly the literature only suggested that trans-faith cooperation and collaboration is pivotal for the success of the humanitarian operation, although, contemporary partnerships between Christian and Islamic organizations are difficult to nurture in post 9/11 geopolitics (Arif 2008). Such difficulties in collaborations have been reported by Clarke (2010), where he explained that it had been complicated for western Christian faith-based or secular organizations to work with their Islamic counterparts in Afghanistan and Iraq.

\section{Research limitations}

Authors of this study believe that data collection from humanitarian organizations is a very challenging and timeconsuming process, and this indeed is one of the limitations of this study. There is a need to bring more depth and breadth to the collected data. Although, the outcome of this study presents statistically significant results, however, a broader data set could bring more confidence in the resulting statements and would be easier to generalize.

\section{Future research direction}

The reasons for differences in opinion are ambiguous, and there is a need to expand this study further. We also agree with Banomyong et al. (2017)), adding more empirical studies in humanitarian literature will open up the gates for discussion on a broader perspective. Moreover, despite a few suggestions from previous researchers, religion is still one of the understudied areas in humanitarian settings. The outcome of this research is just a drop of water in the ocean. Through this study, the respondents have unanimously confirmed the importance of religion in humanitarian settings, and the outcome suggests that the religion of beneficiaries or organizations affiliation with religion could debilitate the success of relief operation. Therefore, the authors of this study firmly believe that there is an imminent need for exploring the active role of religion in different subsets of humanitarian settings. Which also raises the question, if all organizations and actors involved in humanitarian relief are following the principles of neutrality, equality, and impartiality. If they do, then why specific organizations find it easier to work with the people from the same religious beliefs? Why host government access and policies are not consistent for religious and secular organizations?

Table 12 Wilcoxon rank-sum test for internal factors (Christian and Islamic relief organizations)

\begin{tabular}{llllll}
\hline Internal Factors & W-rank Christianity & W-rank Islam & $P$ value & $\begin{array}{c}\text { Priority rank } \\
\text { Christianity }\end{array}$ & $\begin{array}{c}\text { Priority } \\
\text { rank Islam }\end{array}$ \\
\hline Organization's culture & 604.5 & 476.5 & 0.350 & 1 & 6 \\
Coordination and Collaboration & 576.5 & 504.5 & 0.712 & 2 & 5 \\
Religious affiliation of the organization & 575.0 & 506.0 & 0.801 & 3 & 4 \\
Organization's structure & 574.5 & 506.5 & 0.757 & 4 & 3 \\
Internal communication & 555.0 & 526.0 & 0.791 & 5 & 2 \\
Information collection & 507.0 & 574.0 & 0.131 & 6 & 1 \\
\hline
\end{tabular}




\section{Appendix}

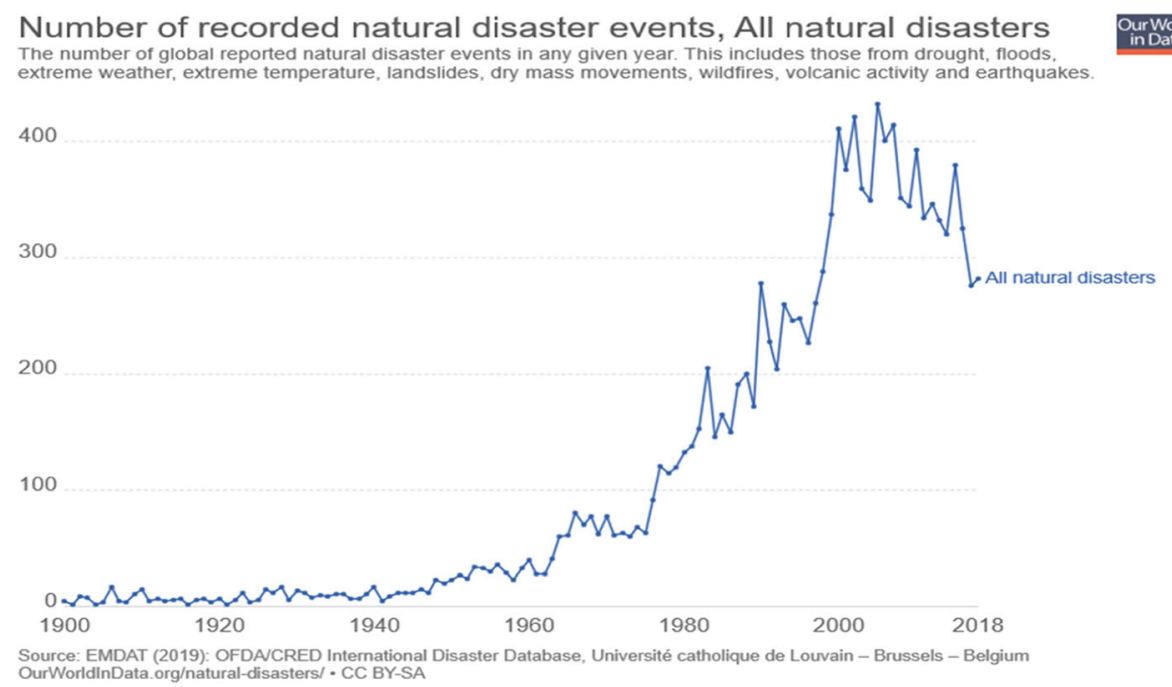

Fig. 2 Natural disaster incidences over time (Ritchie and Roser 2019)

\section{Abbreviations}

CSF: Critical success factors; FBOs: Faith-based organizations;

HOs: Humanitarian organizations; HROs: Humanitarian relief organizations; INGOs: International Non-Governmental Organizations; KSF: Key success factors; NFBOs: Non-faith-based organizations; NGOs: Non-governmental organizations

\section{Author details}

${ }^{1}$ Institute for Transport and Logistics Management, WU, Vienna University of Economics and Business, Welthandelsplatz 1, 1020 Vienna, Austria. ${ }^{2}$ Institute of Statistics, BOKU, University of Natural Resources and Life Sciences, Gregor-Mendel-Straße 33, 1180 Vienna, Austria.

\section{Received: 12 July 2019 Accepted: 29 October 2019}

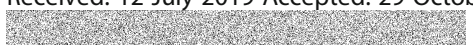

\section{References}

Abidi H, de Leeuw S, Klumpp M (2014) Humanitarian supply chain performance management: a systematic literature review. Supply Chain Manag 19(5/6): 592-608. https://doi.org/10.1108/scm-09-2013-0349

Agresti A, Coull BA (1998) Approximate is better than "exact" for interval estimation of binomial proportions. Am Stat 52(2):119-126. https://doi.org/ 10.1080/00031305.1998.10480550

Aijazi O, Panjwani D (2015) Religion in spaces of social disruption: re-reading the public transcript of disaster relief in Pakistan. Int J Mass Emerg Disasters 33(1):29-55

Arif $Y$ (2008) Religion and rehabilitation: humanitarian biopolitics, city spaces and acts of religion. Int J Urban Reg Res 32(3):671-689. https://doi.org/10.1111/j. 1468-2427.2008.00804.x

Azmat M, Kummer S, Moura LT, Gennaro FD, Moser R (2019) Future outlook of highway operations with implementation of innovative technologies like AV, CV, loT and big data. Logistics 3(2). https://doi.org/10.3390/logistics3020015

Azmat, M., \& Kummer, S. (2019). Importance of key success factors for local and international ngos in humanitarian supply chain. LogForum 15(4), 545-555. https://doi.org/10.17270/J.LOG.2019.372

Balcik B, Beamon BM, Krejci CC, Muramatsu KM, Ramirez M (2010) Coordination in humanitarian relief chains: practices, challenges and opportunities. Int J Prod Econ 126(1):22-34. https://doi.org/10.1016/j.jpe.2009.09.008

Banomyong R, Varadejsatitwong P, Oloruntoba R (2017) A systematic review of humanitarian operations, humanitarian logistics and humanitarian supply chain performance literature 2005 to 2016. Ann Oper Res. https://doi.org/10. 1007/s10479-017-2549-5
Bealt J, Fernández B, Jair C, Mansouri SA (2016) Collaborative relationships between logistics service providers and humanitarian organizations during disaster relief operations. J Humanitarian Logistics Supply Chain Manag 6(2): 118-144. https://doi.org/10.1108/jhlscm-02-2015-0008

Benedetti C (2006) Islamic and Christian inspired relief NGOs: between tactical collaboration and strategic diffidence? J Int Dev 18(6):849. https:/doi.org/10.1002/jid.1318

Besiou M, Stapleton O, Van Wassenhove LN (2011) System dynamics for humanitarian operations. J Humanitarian Logistics Supply Chain Manag 1(1): 78-103. https://doi.org/10.1108/20426741111122420

Bland JM, Altman DG (1997) Statistics notes: Cronbach's alpha. Bmj 314(7080):572

Burkart C, Besiou M, Wakolbinger T (2016) The funding-humanitarian supply chain interface. Surv Oper Res Manag Sci 21(2):31-45. https://doi.org/10. 1016/j.sorms.2016.10.003

Celik E, Gumus AT, Alegoz M (2014) A trapezoidal type-2 fuzzy MCDM method to identify and evaluate critical success factors for humanitarian relief logistics management. J Intell Fuzzy Syst 27(6):2847-2855. https:/doi.org/10.3233/ifs-141246

Clarke G (2010) Trans-faith humanitarian partnerships: the case of Muslim aid and the united Methodist committee on relief. Eur J Dev Res 22(4):510-528. https://doi.org/10.1057/ejdr.2010.22

Corder, G. W., \& Foreman, D. I. (2014). Nonparametric statistics: A step-by-step approach. Hoboken: Wiley.

Costa SR, Campos VG, Bandeira RA (2012) Supply chains in humanitarian operations: cases and analysis. Procedia Soc Behav Sci 54:598-607. https:// doi.org/10.1016/.j.sbspro.2012.09.777

da Costa SRA, Bandeira RAM, Mello L, Campos VBG (2014) Humanitarian supply chain: an analysis of response operations to natural disasters. Eur J Transp Infrastruct Res 14(3):290-310

Dale JM, Dulaimi MF (2016) Cultural competence-a success factor in NGO projects? Built Environ Proj Asset Manage 6(2):232-246. https://doi.org/10 1108/bepam-08-2014-0038

Dasaklis TK, Pappis CP (2018) Critical success factors for implementing cholera vaccination campaigns in humanitarian emergencies: a DEMATEL-based approach. Euro J Decis Processes 6(1-2):1-20. https:/doi.org/10.1007/s40070-017-0062-3

Day JM, Junglas I, Silva L (2009) Information flow impediments in disaster relief supply chains. J Assoc Inf Syst 10(8):637-660

Day JM, Melnyk SA, Larson PD, Davis EW, Whybark DC (2012) Humanitarian and disaster relief supply chains: a matter of life and death. J Supply Chain Manag 48(2):21-36

De Cordier B (2009) The 'Humanitarian Frontline', development and relief, and religion: what context, which threats and which opportunities? Third World Q 30(4):663-684. https://doi.org/10.1080/01436590902867086 
Dube, N., Van der Vaart, T., Teunter, R. H., \& Van Wassenhove, L. N. (2016). Host government impact on the logistics performance of international humanitarian organisations. Journal of Operations Management, 47:44-57.

Eriksson, M., \& Karlsson, E. (2017). Critical success factors' impact on agility of humanitarian supply chains. (masters master thesis), Jonkoping university Jonkoping, Sweden. Retrieved from http://www.diva-portal.org/smash/get/ diva2:1120250/FULLTEXT01.pdf

Ferris, E. (2005). Faith-based and secular humanitarian organizations. Retrieved from

Fountain PM, Kindon SL, Murray WE (2004) Christianity, calamity, and culture: the involvement of Christian churches in the 1998 Aitape tsunami disaster relief. Contemporary Pacific 16(2):321-355. https://doi.org/10.1353/cp.2004.0045

Goldsmith, S., Eimicke, W., \& Pineda, C. (2006). Faith-based organizations versus their secular counterparts: a primer for local officials. Retrieved from

Grung AH (2018) Negotiating gender justice between state, religion, and NGOs: a Lebanese case. Religions 9(6):12. https://doi.org/10.3390/rel9060175

Hackett, C., \& McClendon, D. (2017). Christians remain world's largest religious group, but they are declining in Europe. Retrieved from https://www. pewresearch.org/fact-tank/2017/04/05/christians-remain-worlds-largestreligious-group-but-they-are-declining-in-europe/

Haynes W (2013) Wilcoxon rank sum test. Encyclopedia of systems biology, pp 2354-2355

Jayasinghe S (2007) Faith-based NGOs and healthcare in poor countries: a preliminary exploration of ethical issues. J Med Ethics 33(11):623-626. https:// doi.org/10.1136/jme.2006.018549

Kabra G, Ramesh A (2015a) Analyzing drivers and barriers of coordination in humanitarian supply chain management under fuzzy environment. Benchmarking 22(4):559-587. https://doi.org/10.1108/bij-05-2014-0041

Kabra G, Ramesh A (2015b) Segmenting critical factors for enhancing the use of IT in humanitarian supply chain management. Procedia Soc Behav Sci 189: 144-152. https://doi.org/10.1016/j.sbspro.2015.03.208

Kabra G, Ramesh A, Arshinder K (2015) Identification and prioritization of coordination barriers in humanitarian supply chain management. Int J Disaster Risk Reduction 13:128-138. https://doi.org/10.1016/j.jdrr.2015.01.011

Kraft K, Smith JD (2019) Between international donors and local faith communities: intermediaries in humanitarian assistance to Syrian refugees in Jordan and Lebanon. Disasters 43(1):24-45. https://doi.org/10.1111/disa.12301

Larson PD (2005) A note on mail surveys and response rates in logistics research. J Bus Logist 26(2):211-222. https://doi.org/10.1002/j.2158-1592.2005.tb00212.x

Leiras A, de Brito Jr I, Queiroz Peres E, Rejane Bertazzo T, Hugo T, Yoshida Y (2014) Literature review of humanitarian logistics research: trends and challenges. J Humanitarian Logistics Supply Chain Manag 4(1):95-130. https://doi.org/10.1108/jhlscm-04-2012-0008

Lijo J, Gurumurthy A, Soni G, Jain V (2018) Modelling the inter-relationship between factors affecting coordination in a humanitarian supply chain: a case of Chennai flood relief. Ann Oper Res 1:-32. https://doi.org/10.1007/ s10479-018-2963-3

Martinez, A. J. P., Stapleton, O., \& Van Wassenhove, L. N. (2011). Field vehicle fleet management in humanitarian operations: a case-based approach. Journal of operations management 29(5):404-421.

McLachlin R, Larson PD (2011) Building humanitarian supply chain relationships: lessons from leading practitioners. J Humanitarian Logistics Supply Chain Manag 1(1):32-49. https://doi.org/10.1108/20426741111122402

McLachlin R, Larson PD, Khan S (2009) Not-for-profit supply chains in interrupted environments: the case of a faith-based humanitarian relief organisation MRN. Manag Res News 32(11):1050-1064. https://doi.org/10.1108/ 01409170910998282

Meek GE, Ozgur C, Dunning K (2007) Comparison of the t vs. Wilcoxon signedrank test for Likert scale data and small samples. J Mod Appl Stat Methods 6(1):91-106. https://doi.org/10.22237/jmasm/1177992540

Moshtari M, Gonçalves P (2016) Factors influencing Interorganizational collaboration within a disaster relief context. Volunt Int J Volunt Nonprofit Org 28(4):1673-1694. https://doi.org/10.1007/s11266-016-9767-3

Ngwenya NK, Naude MJA (2016) Supply chain management best practices: a case of humanitarian aid in southern Africa. J Transp Supply Chain Manage 10(1):242. https://doi.org/10.4102/jtscm.v10i1.242

Okkenhaug IM (2015) Religion, relief and humanitarian work among Armenian women refugees inMandatory Syria, 1927-1934. Scand J Hist 40(3):432-454. https://doi.org/10.1080/03468755.2015.1043641

Oloruntoba R (2010) An analysis of the cyclone Larry emergency relief chain: some key success factors. Int J Prod Econ 126(1):85-101. https://doi.org/10 1016/j.jpe.2009.10.013
Paulson N, Menjivar C (2012) Religion, the state and disaster relief in the United States and India. Int J Sociol Soc Policy 32(3-4):179-196. https://doi.org/10. $1108 / 01443331211214758$

Pettit S, Beresford A (2009) Critical success factors in the context of humanitarian aid supply chains. Int J Phys Distrib Logistics Manage 39(6):450-468. https:// doi.org/10.1108/09600030910985811

Ritchie, H., \& Roser, M. (2019). Natural Disasters. Retrieved from https:// ourworldindata.org/natural-disasters

Rivera JD (2018) Reliance on faith-based organizations for tangible assistance in times of disaster: exploring the influence of bonding social capital. Sociol Spectr 38(1):39-50. https://doi.org/10.1080/02732173.2017.1409147

Rodon J, Maria Serrano JF, Giménez C (2012) Managing cultural conflicts for effective humanitarian aid. Int J Prod Econ 139(2):366-376. https://doi.org/10. 1016/j.jpe.2011.08.029

Samuels J (2016) Buddhist disaster relief monks, networks, and the politics of religion. Asian Ethnol 75(1):53-74

Sandwell C (2011) A qualitative study exploring the challenges of humanitarian organisations. J Humanitarian Logistics Supply Chain Manag 1(2):132-150. https://doi.org/10.1108/20426741111158430

Scholten, K., Sharkey Scott, P., \& Fynes, B. (2010). (Le) agility in humanitarian aid (NGO) supply chains. International Journal of Physical Distribution \& Logistics Management 40(8/9):623-635.

Sridhar KM, Nagabhushanam M (2008) NGOs in India- uniqueness and critical success factors, results of an FGD. Vision 12(2):15-21. https://doi.org/10.1177/ 097226290801200202

Stajura M, Glik D, Eisenman D, Prelip M, Martel A, Sammartinova J (2012) Perspectives of community- and faith-based organizations about partnering with local health departments for disasters. Int J Environ Res Public Health 9(7):2293-2311. https://doi.org/10.3390/ijerph9072293

Tatham P, Houghton L (2011) The wicked problem of humanitarian logistics and disaster relief aid. J Humanitarian Logistics Supply Chain Manag 1(1):15-31. https://doi.org/10.1108/20426741111122394

Tavakol M, Dennick R (2011) Making sense of Cronbach's alpha. Int J Med Educ 2 : 53-55

Tremblay-Boire J, Prakash A (2019) Biased altruism: Islamophobia and donor support for global humanitarian organizations. Public Adm Rev 79(1):113124. https://doi.org/10.1111/puar.13012

Van Wassenhove LN (2017) Humanitarian aid logistics: supply chain management in high gear. J Oper Res Soc 57(5):475-489. https://doi.org/10.1057/palgrave. jors. 2602125

WANGO. (2000). About world association of non-governmental organizations (WANGO). Retrieved from https://www.wango.org/about.aspx

Wilcoxon F, Katti S, Wilcox RA (1970) Critical values and probability levels for the Wilcoxon rank sum test and the Wilcoxon signed rank test. Selected tables in mathematical statistics, vol 1, pp 171-259

Yadav DK, Barve A (2015) Analysis of critical success factors of humanitarian supply chain: an application of interpretive structural modeling. Int J Dis Risk Reduction 12:213-225. https://doi.org/10.1016/.ijdrr.2015.01.008

Yadav DK, Barve A (2018) Segmenting critical success factors of humanitarian supply chains using fuzzy DEMATEL. Benchmarking 25(2):400-425. https://doi. org/10.1108/BIJ-10-2016-0154

\section{Publisher's Note}

Springer Nature remains neutral with regard to jurisdictional claims in published maps and institutional affiliations. 